\title{
The Black-billed Magpie
}

Photos by Murray Gibson, Saskatoon

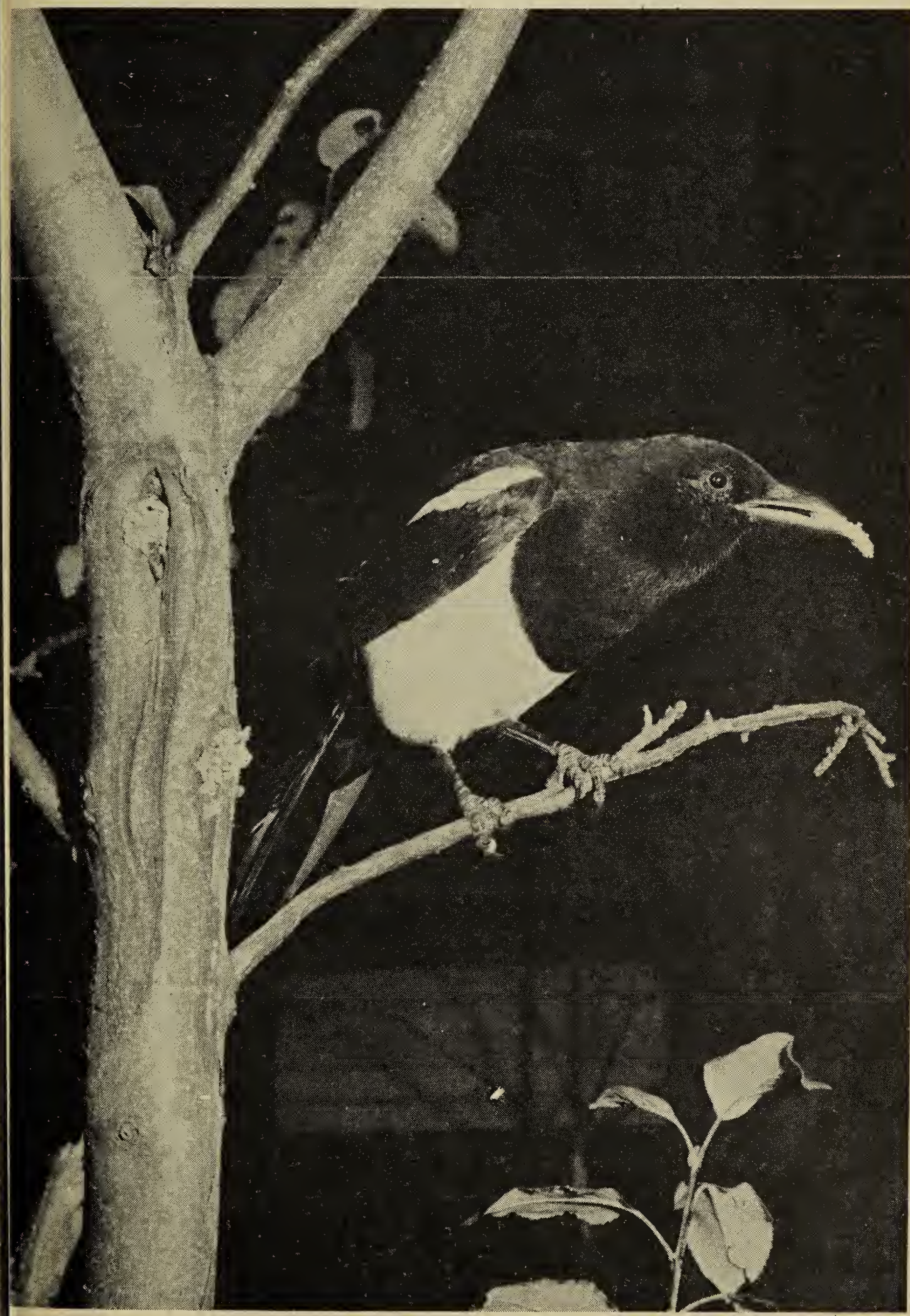

The Black-billed Magpie, under observation at the Compbell home, is photographed feeding. 


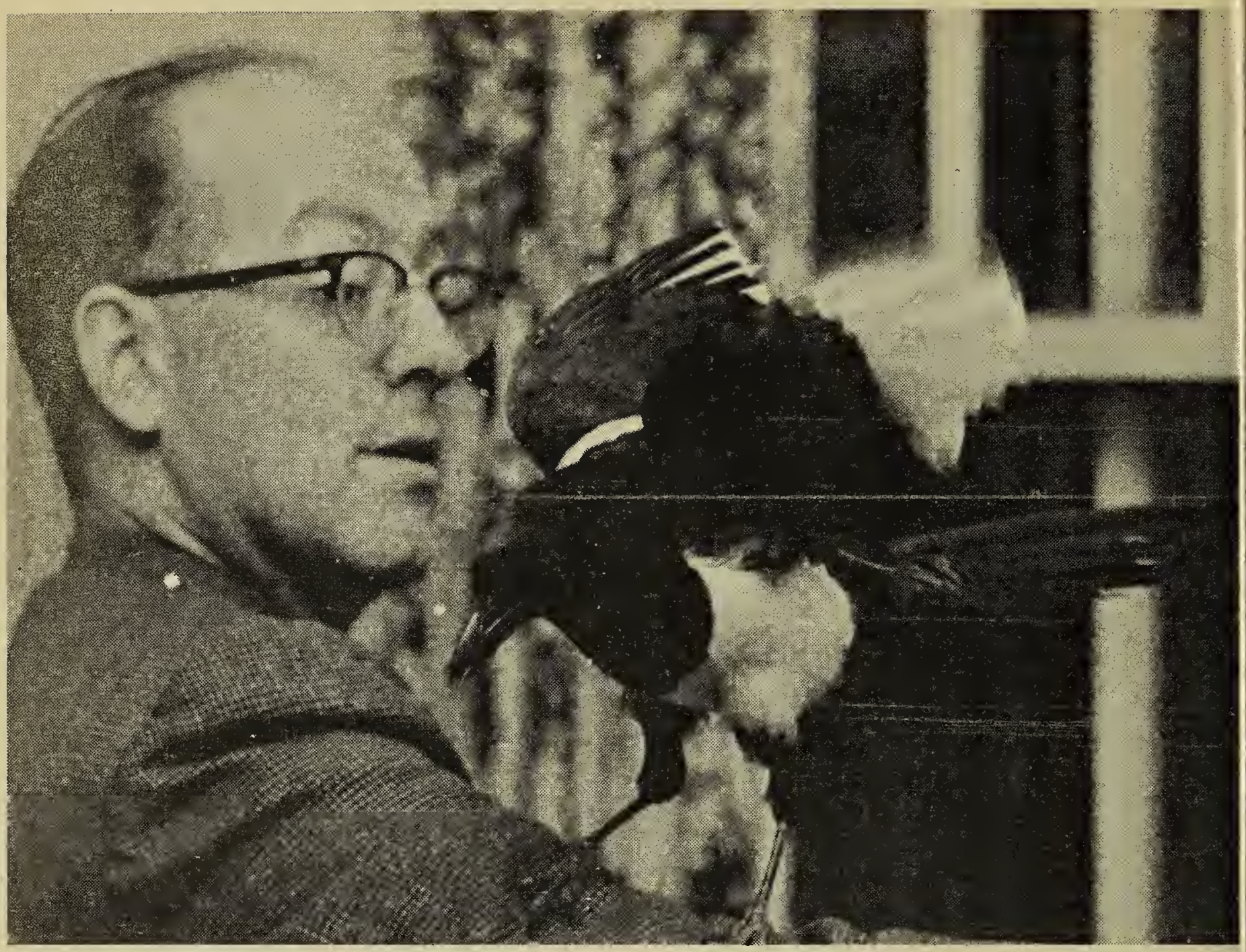

Joe Compbell watches the magpie's ontics with amused surprise.

Ordinarily, wild birds and animals are enjoyed most in their natural surroundings, and people living in the country are fortunate in being able to watch them. Sometimes, however, when a bird or animal has been introduced as a "pet" into a city home, rather unusual observations are made by the persons who live in close proximity to it. The Campibells in Saskatoon took a young Black-billed Magpie that was just learning to fly when they were vacationing at Little Lake Manitou in the summer of 1962 , and brought it back to the city.

After being captive a few days so that it would become familiar with its new surroundings, "Mr. Joe," as the magpic was affectionately named by the children, was given the freedom of the city. It was not long before the neighbours, as well as the Camphells, became interested in the young magpie and its behaviour. In the school yard he seemed fond of the children and would skip along after them when they played, making the most unexpected sounds.

Mr. Campbell tells how the magpie would station itself on a branch outside the dining room window when they sat down to supper, and look in upon their activities. The Campbells found him " a most intelligent, and at the same time most comical bird, and on top of that a strikingly beautiful creature with his long, sleek, shimmering tail and his contrasting markings of black and white."

Being allowed to wander at will, the magpie could find food for himself, but the Campibells supplemented his diet with raw meat, raw eggs and, in summer, hordes of grasshoppers which he appeared to consider a delicacy.

Unhappily, the Campibells lost their pet magpie - it was maimed and then killed, probably by someone who shared the rather common concept of the magpie as "vermin." The life history and feeding habits of this bird are not completely known, and there is some disagreement about its role. The Campbells, by having the magpie living with them, came to appreciate the handsome bird and to take a real interest in studying its behaviour. 